\title{
Diagnostic Dilemma in Typhoid Fever-Real Time PCR, Need of the Hour
}

\author{
Namita Srivastava $^{1 *}$, Ashwani Kumar ${ }^{1}$, N.P. Singh ${ }^{1}$ and Vikas Manchanda ${ }^{2}$ \\ ${ }^{1}$ Department of Microbiology, University College of Medical Sciences and Guru \\ Tegh Bahadur Hospital, Delhi, India \\ ${ }^{2}$ Department of Microbiology, Maulana Azad Medical College, Delhi, India \\ *Corresponding author
}

\begin{abstract}
A B S T R A C T
Typhoid fever is an important public health problem. According to a press release from the Press Information Bureau, Government of India, dated 22 February 2006, the morbidity due to typhoid fever varies from 102 to 2,219 per 100,000 population in different parts of India, and in some areas, typhoid fever is responsible for 2 to $5 \%$ of all deaths. Gold standard for diagnosis of typhoid fever is blood culture, but it is time-consuming and takes several days for isolation and identification of causative organisms. Serological tests have very low sensitivity and specificity, and of little practical value in endemic areas. However for optimal management, early diagnosis of the disease and prompt treatment are essential. Therefore a rapid and sensitive detection method for typhoid fever is urgently needed. Method Blood sample was taken from 100 suspected typhoid cases for conventional blood culture, BACTEC blood culture and real time PCR. Blood culture was performed using standard protocol. real time PCR targeting the prg K gene was performed on all the 100 samples. Results: Out of 100 suspected typhoid cases blood culture and Bactec were positive in 24 cases. There were no differences in yield of Conventional and Bactec blood cultures. The Real time assay identified 20 cases (83\%) as positives among the 24 culture positive cases. However, the assay additionally detected 20 (26\%) of cases as Salmonella infections among culture negative patients. The sensitivity and specificity of Real Time PCR assay was determined to be $83.33 \%$ and $73.68 \%$ using blood culture as gold standard. . Conclusion It is thus concluded that PCR is a rapid, sensitive, and specific test for the diagnosis of typhoid fever, especially where blood culture was negative because of prior antibiotic treatment and culture done in late stages of disease, thus enabling the clinician to use appropriate treatment and to avoid diagnostic delay
\end{abstract}

\section{Introduction}

Typhoid fever caused by Salmonella typhi is an important public health problem. The World Health Organization (WHO) estimate for annual global incidence of typhoid fever, is about 21 million cases and 216,000 deaths every year (Crump et al., 2004). Enteric fever is still a common disease in many parts of the world where supply of clean water is limited.
In countries such as India, Nepal, Pakistan, Indonesia and parts of sub-Saharan Africa, typhoid is still a substantial public health problem (Bhan, 2005). In these areas, as febrile disease is common, accurate diagnosis is the need of hour, particularly as antimicrobial resistance is emerging (Chau et al., 2007). 
The clinical diagnosis of typhoid fever is not sufficient, as the symptoms it causes overlap with those of other febrile illnesses and are mostly nonspecific. Parameters such as relative bradycardia or leucopoenia may be useful (Khan et al., 1998) but give a low specificity. Confirmation of typhoid fever requires the identification of Salmonella typhi in clinical specimens. Blood culture of Salmonella typhi, while considered "routine", is expensive and has its own limitations. It is time-consuming and takes at least 2 to 5 days until the identification of the organism. Blood culture can identify 45 to $70 \%$ of patients with typhoid fever, depending on various factors like the amount of blood sampled, the bacteraemic level of the bacilli, type of culture medium used, and the length of incubation period (Wain et al., 2001), Diagnostics based on serology, are available but have limitations. Several serological assays for detecting Salmonella typhi antigens or antibodies have been used for the rapidity and simplicity, but they are not highly sensitive and specific (Rubin et al., 1988).

The development of cheap and reliable enteric fever diagnostics would undoubtedly benefit long term disease control and treatment.

\section{Materials and Methods}

The study was done in the Department of Microbiology, at University College of Medical Sciences and Guru Tegh Bahadur Hospital, Delhi from 2011 to 212.A preformatted questionnaire was used for selection of 100 patients with suspected enteric fever to be included in the study. The history included clinical presentation of the patients with duration of fever, associated symptoms, signs and complications, if any. History of antibiotic intake, previous history of enteric fever and results of current associated investigations done if any were also included. Only those cases suspected of having enteric fever according to the preforms were included in the study.

Peripheral blood samples were collected from these patients for:

Blood culture: $5 \mathrm{ml}$ blood in $50 \mathrm{ml}$ of BHIB (i.e., 1:10 dilution)

Bactec: $8 \mathrm{ml}$ blood in adult Bactec

PCR: $2 \mathrm{ml}$ blood in EDTA vial

DNA extraction was done from blood samples within 4 days of collection and the lysate was store at $-4^{0} \mathrm{C}$.

30 non typhoid febrile subjects with an established alternative diagnosis of malaria were also included as control.

Blood culture by conventional method and BACTEC 9120 was performed following standard protocol. Cultures showing growth were subjected to identification of the organism by hanging drop, gram stain and battery of biochemical tests.

Final identification of the organisms was done by slide agglutination with specific antisera.

\section{Processing of blood samples for real time PCR}

Blood samples were collected in EDTA vials. Extraction of DNA was done as per protocol described in Genomic DNA Extraction Kit by BIONEER. The lysate was stored at $-20^{\circ} \mathrm{C}$.

\section{Real Time PCR amplification protocol}

\section{Real time amplification protocol based on prg $\mathrm{K}$ geneof Salmonella entrica}

For Real Time PCR, master mix was prepared as per manufacturer (ROCHE) instruction. Master mix for a single reaction was prepared by mixing $0.5 \mu \mathrm{l}$ each of forward primer, 
reverse primer. Ten microliters of Sybr Green probe master and $6 \mu \mathrm{l}$ of distilled water were added to it, so that for a single reaction, $17 \mu 1$ of master mix solution was prepared. 96 wells special plate (Roche) was used in light cycler 480 to run Real Time PCR reaction. In each well $17 \mu \mathrm{l}$ master mix was added with $3 \mu l$ specimen DNA. Pure culture DNA extract of Salmonella typhi, Salmonella paratyphi A, Salmonella paratyphi B, Salmonella arizonaewere used as positive control, and Escherichia coli, Acinetobacter baumannii, Streptococcus pneumoniae were used as negative controls.

Plates were sealed with sealing foil.

\section{Statistical analysis}

Sensitivity and specificity was calculated. The Kappa value was determined to find agreement between Real Time PCR, conventional blood culture and Bactec blood culture.

\section{Results and Discussion}

Age of the cases ranged from 19 yrs. to 56 yrs. (mean age 37.5 years). Male to Female ratio among patients included in the study was 1.22:1.Fever was present in $100 \%$ of cases. Abdominal pain and chills were seen among almost half of the cases. Common findings on examination apart from increased body temperature included splenomegaly (25\%). Hepatomegaly (21\%) and bradycardia (12\%) (Table 2).

Majority of the patients included (79\%) said that no antibiotic has been consumed before visiting the hospital. A total of $21 \%$ patients had history of antibiotic intake before visiting the hospital. In this study paired non-repeat blood specimens (Brain Heart Infusion Broth and Bactec blood culture) were collected from each of 100 suspected typhoid fever cases. Blood culture grew Salmonella typhi in 24 patients. Rest of the cultures was sterile after 7 days of incubation. No other bacterial species was isolated in these patients. No patient with history of prior antibiotic intake has positive blood culture. There were no differences in yield of Conventional and Bactec blood cultures.

Real time PCR assay was designed using prg $K$ gene. Assay was standardised using Sybr Green chemistry. Pure culture DNA extract of Salmonella typhi, Salmonella paratyphi A, Salmonella paratyphi B, Salmonella arizonae were used as positive control, and Escherichia coli, Acinetobacter baumannii, Streptococcus pneumoniae were used as negative controls.

A total of $40 \%$ of the patients were confirmed to have Salmonella infection using real time PCR ( $\operatorname{rg} K$ gene). The Real time assay identified 20 cases $(83 \%)$ as positives among the 24 culture positive cases. However, the assay additionally detected 20 (26\%) of cases as Salmonella infections among culture negative patients. The sensitivity and specificity of Real Time PCR assay was determined to be $83.33 \%$ and $73.68 \%$ using blood culture as gold standard.

Use of blood culture as a screening test in patients with fever yield lower positivity rate for $S$. typhi. The positivity rate in such cases varies from $9 \%$ to $27 \%$ in several studies (Kundu Retal, 2006). High variation in isolation rates have been attributed to the amount of blood subjected to culture, the level of bacteremia, the type of culture medium used, stage of illness and prior exposure to antibiotics (Wain et al., 2001). In present study, a positivity rate of $24 \%$ was observed. Interestingly, yield of conventional blood culture was in complete agreement with the Bactec blood culture. Lower than expected yield of blood culture was observed despite paired blood cultures (one conventional and one Bactec culture). This was probably due to prior intake of antibiotics 
by the patients, although only $21 \%$ of patients gave history of prior antibiotic intake at the time of blood collection. Also, it is possible that many of the remaining patients were ignorant of their prior antibiotic intake leading to lower positivity rates in our study. Improved yield of blood culture have been reported with isolation rates ranging from 45 to $70 \%$ of patients with suspected typhoid fever (Wain, et al., 2001). Given the limitations associated with blood culture techniques for the diagnosis of typhoid fever, in this study, PCR technique was used for detection of Salmonella serovar typhi. Several studies have attempted PCR assay from blood, stool, bile, urinary specimen with limited success. (Chaudhry Retal, 1997; Farrell et al., 2005).

Evaluation of PCR as a diagnostic tool for typhoid fever dates back to 1993 when Song et $a l$., successfully amplified the flagellin gene $(f l i C-d)$ of Salmonella serovar typhi in all cases of culture proven typhoid fever and from none of the healthy controls (Song et al., 1993).

Studies using different genes and primer sets have been utilised to detect Salmonella typhi through PCR techniques.

We designed an assay using prg $K$ gene (Farrell JJ, et al., 2005), prg $K$ gene, is a part of genetic complex that is thought to be important for enterocyte invasion. This assay was standardised using Syber Green chemistry. The real time PCR assay identified 40 cases of Salmonella infection in 100 clinically suspected cases. We found the potential advantage of real time PCR in that it may be performed on smaller volumes of blood than required for culture. Another advantage of the PCR assay is its ability in diagnosing patients with history of prior antibiotic intake this is probably the reason for detection of additional four cases by PCR assay among patients with history of antibiotic intake in our study.

Fig.1 Melting curve analysis of few of the clinical specimens with real Time PCR Assay using primers from $\operatorname{prg} K$ gene. (Negative specimens can be seen as blue lines and positive specimens have melting peaks with Tm between 84.3 to 85.3 )

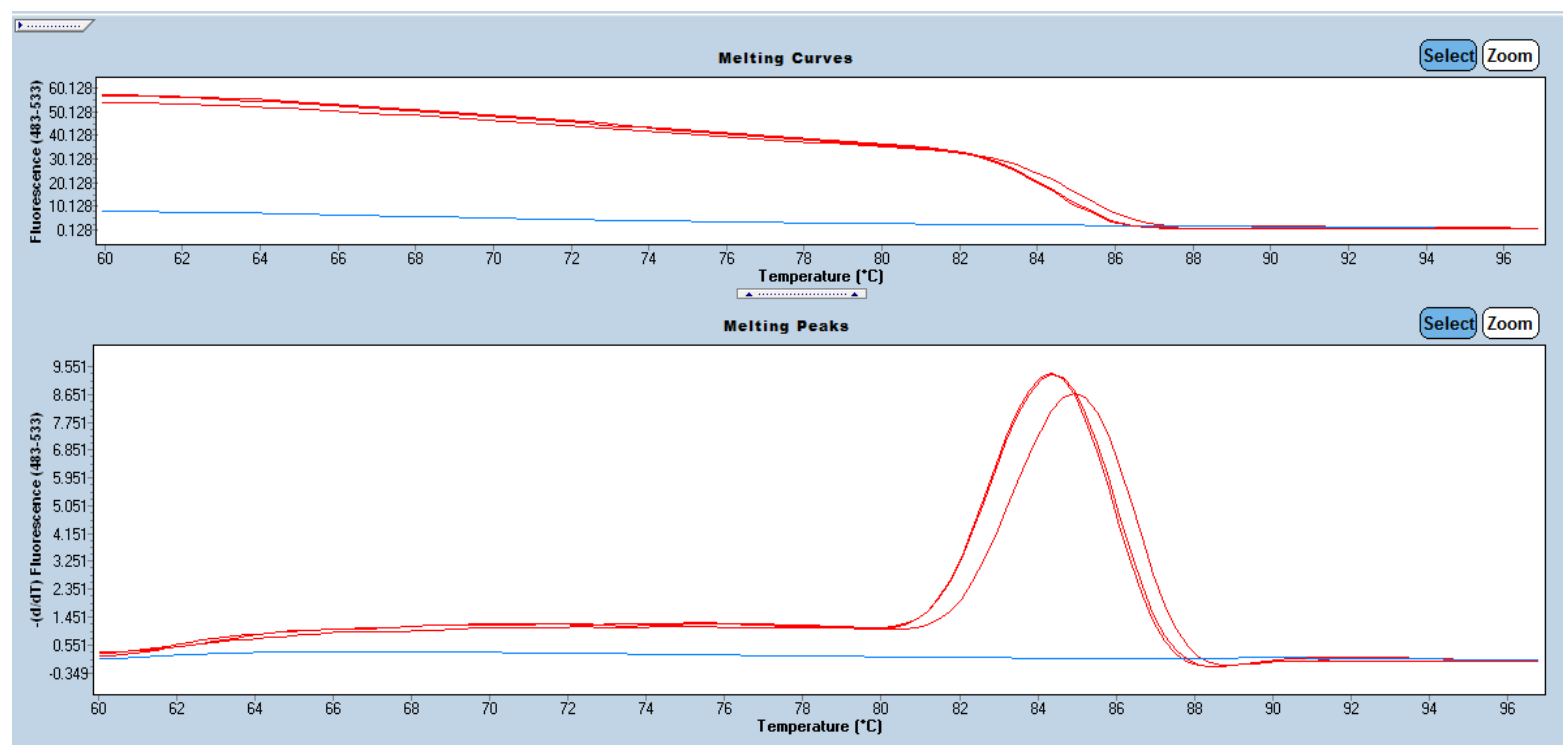


Fig.2 Melting curve analysis of few of the clinical specimens with real Time PCR Assay using primers from $\operatorname{prg} K$ gene. (Negative specimens can be seen as blue lines and positive specimens have melting peaks with Tm between 84.3 and 85.3 )

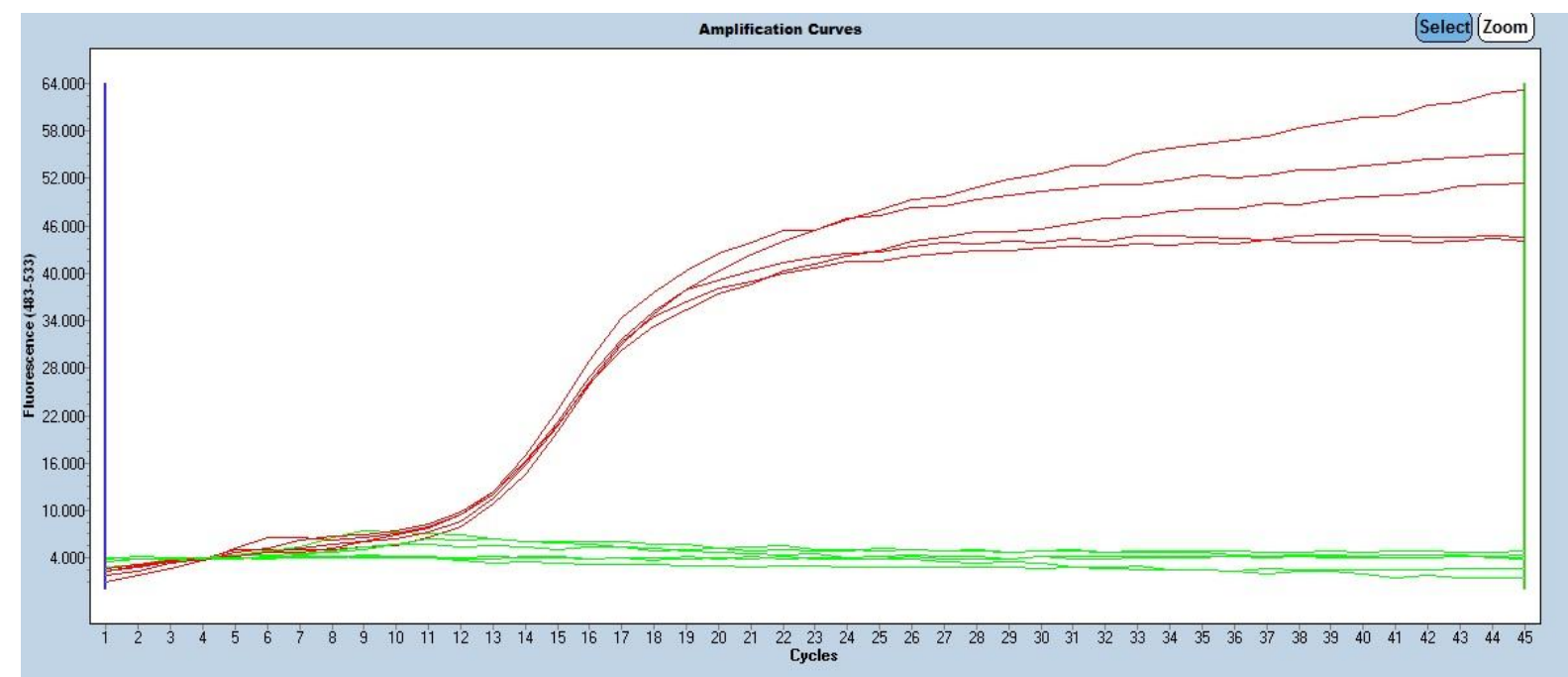

Real Time PCR Assay of clinical specimens using primers from prg $K$ gene the positive samples had crossing point values (Cp values) of 11-13 cycles

Table.1 PCR conditions

\begin{tabular}{|lllllll|}
\hline $\begin{array}{l}\text { Preincubation- } \\
\text { Denaturation }\end{array}$ & 1 & None & 95 & None & $00: 05: 00$ & 4.4 \\
$\begin{array}{l}\text { Amplification } \\
\text { Mmelting }\end{array}$ & 45 & Quantificaton & 95 & None & $00: 00: 10$ & 4.4 \\
& & & 59 & None & $00: 00: 20$ & 2.2 \\
& \multirow{2}{*}{1} & Melting & 95 & Single & $00: 00: 20$ & 4.4 \\
& & curves & & None & $00: 00: 05$ & 1.5 \\
\hline
\end{tabular}

Plates were inserted in Light Cycler 480 (ROCHE) and results were obtained.

In the present study PCR could detect more number of typhoid cases $(40 \%)$ than blood culture $(24 \%)$. Additional cases of typhoid fever with positive PCR results can be probably due to the fact, that few patients were ignorant of antibiotic intake thus were blood culture negative leading to lower blood culture positivity rates but were detected through PCR technique. Hence, this test may be helpful in settings where patients are using antibiotics as over the counter drugs.

However, there were four culture positive cases which were negative by PCR; the cause of which could be attributed to lower bacterial count $/ \mathrm{ml}$ of blood. The similar observation was made in another study, where authors attributed a lack of sensitivity of the assay to the low physiological level of invasive Salmonella organisms in the blood (Nga et al., 2010).

In the present study, the sensitivity and specificity of real time PCR assay was determined to be $83.3 \%$ and $73.7 \%$ using blood culture as gold standard. Keeping in view that all positive PCR cases are giving similar melting curves, it may be presumed that all the PCR positive cases are true positive cases. Similar melting curves were obtained for culture positive - PCR positive cases and PCR positive - culture negative 
cases. Thus, it can be presumed that all PCR positive cases which were from culture negative samples are true positives. Hence, taking PCR as gold standard, the sensitivity of blood culture was found to be $50 \%$.

Thus, PCR using $\operatorname{prg} K$ gene was found suitable in our setting. PCR detection of Salmonella typhi took less than 24 hours, compared with three to five days for blood culture. Therefore, PCR was a rapid, sensitive, and specific test for the diagnosis of typhoid fever, especially where blood culture was negative because of prior antibiotic treatment and culture done in late stages of disease, thus enabling the clinician to use appropriate treatment and to avoid diagnostic delay.

\section{References}

Bhan, M.K., Bahl R, Bhatnagar S. Typhoid and paratyphoid fever. Lancet 2005; 366 (9487): 749-62.

Chau, T.T., Campbell JI, Galindo CM, Van Minh Hoang N, Diep TS, Nga TT, et al., Antimicrobial drug resistance of Salmonella enterica serovarTyphi in asia and molecular mechanism of reduced susceptibility to the fluoroquinolones. Antimicrob Agents Chemother 2007; 51(12): 4315-23.

Chaudhry, R., Laxmi BV, Nisar N, Ray K, Kumar D. Standardisation of polymerase chain reaction for the detection of Salmonella typhi in typhoid fever. J Clin Pathol 1997; 50: 437-9

Crump, J.A., Luby SP, Mintz ED. The global burden of typhoid fever. Bull World
Health Organ 2004; 82: 346-53.

Farrell, J.J., Doyle LJ, Addison RM, Reller LB, Hall GS, Procop GW. Broad-Range (Pan) Salmonella and Salmonella Serotype typhi-Specific Real-Time PCR Assays. Am J ClinPathol 2005; 123: 339-45?

Khan, M., Coovadia YM, Connoly C, Sturm AW. The early diagnosis of typhoid fever prior to the Widal test and bacteriological culture results. Acta Tropica 1998; 69: 165-73.

Kundu, R., Ganguly N, Ghosh TK, Yewale VN, Shah RC, Shah NK. IAP TaskForce Report: diagnosis of enteric fever in children. Indian Pediatr 2006; 43(10): 875-83

Nga, T.V., Karkey A, Dongol S, Thuy HN, Dunstan S, Holt K, et al., The sensitivity of real-time PCR amplification targeting invasive Salmonella serovars in biological specimens. BMC Infect Dis 2010; 10: 125

Rubin, F.A., Kopecko DJ, Sack RB, Sudarmono P, Yi A, Maurta D, et al., Evaluation of a DNA probe for identifying Salmonella typhi in Peruvian and Indonesian bacterial isolates. J Infect Dis 1988; 157: 1051-3.

Song, J.H., Cho H, Park MY, Na DS, Moon HB, Pai CH. Detection of Salmonella typhi in the blood of patients with typhoid fever by polymerase chain reaction. J ClinMicrobiol 1993; 31: 1439-43.

Wain, J., Pham VB, Ha V, Nguyen NM, To SD, Walsh AL, et al., Quantitation of Bacteria in Bone Marrow from Patients with Typhoid Fever: Relationship between Counts and Clinical Features. J Clin Microbiol 2001; 39: 1571-6.

\section{How to cite this article:}

Namita Srivastava, Ashwani Kumar, N.P. Singh and Vikas Manchanda. 2017. Diagnostic Dilemma in Typhoid Fever- Real Time PCR, Need of the Hour. Int.J.Curr.Microbiol.App.Sci. 6(9): 3012-3017. doi: https://doi.org/10.20546/ijcmas.2017.609.369 